\title{
Non-cognitive Personality Assessment and Risk of Injuries Among Army
}

\section{Trainees}

Alexis A. Oetting, MPH, ${ }^{1,2}$ Nadia U. Garvin, MHS, ${ }^{1,2}$ Michael R. Boivin, MD, MPH, ${ }^{1}$ David N.

Cowan, $\mathrm{PhD}, \mathrm{MPH}^{1,2}$

From the ${ }^{1}$ Walter Reed Army Institute of Research, Silver Spring, Maryland; and ${ }^{2}$ ManTech Health, Herndon, Virginia

Address correspondence to: David N. Cowan, PhD, MPH, Preventive Medicine, Walter Reed Army Institute of Research, 503 Robert Grant Avenue, Silver Spring MD 20910. E-mail: david.n.cowan.ctr@mail.mil. 
Introduction: Low levels of pre-accession physical fitness and activity are risk factors for stress fractures and other overuse musculoskeletal injuries among military trainees. One dimension in the Tailored Adaptive Personality Assessment System (TAPAS), a non-cognitive personality test given to Army applicants, specifically assesses propensity to engage in physical activity. This dimension may serve as a surrogate measure for activity or fitness. The study examines the associations between TAPAS dimension scores and risk of musculoskeletal injuries.

Methods: Fifteen TAPAS dimension scores for 15,082 U.S. Army trainees entering military service in 2010 were provided by the U.S. Army Research Institute for Social and Behavioral Sciences. During 2013-2015, the associations between TAPAS dimension scores (as a continuous variable) and injuries in the first 6 months of service were evaluated using logistic regression, with the measure of association being the OR.

Results: The TAPAS physical conditioning dimension was associated with musculoskeletal injuries and stress fractures among both men (musculoskeletal injury, $\mathrm{OR}=0.83,95 \% \mathrm{CI}=0.79$, 0.86; stress fracture, $\mathrm{OR}=0.68,95 \% \mathrm{CI}=0.57,0.80$ ) and women (musculoskeletal injury, $\mathrm{OR}=0.77,95 \% \mathrm{CI}=0.70,0.85$; stress fracture, $\mathrm{OR}=0.60,95 \% \mathrm{CI}=0.43,082$ ). No other dimensions were both significantly and consistently associated with either injury. Conclusions: The TAPAS physical conditioning dimension is a strong predictor of musculoskeletal injury and stress fracture among male and female U.S. Army trainees, and may serve as a pre-accession screen for self-reported physical activity. 


\section{Introduction}

Stress fractures and other overuse musculoskeletal injuries (MSIs) are a major cause of morbidity and lost training time among military trainees. ${ }^{1-3}$ A number of risk factors for MSIs and stress fractures have been identified, including level of physical fitness on military entry and history of physical activity. ${ }^{4-8}$ In the U.S. Army, neither pre-accession physical fitness nor physical activity levels are measured currently.

Non-cognitive personality assessments have been studied as predictors of job performance and as tools for personnel selection in civilian and military work settings. ${ }^{9-13}$ Non-cognitive attributes such as personality, interests, and values have been shown to be significantly associated with entry-level soldier performance and retention. ${ }^{14-20}$ The Tailored Adaptive Personality Assessment System (TAPAS) was created for use by the U.S. Army to measure personality dimensions that could predict motivational outcomes such as job effort, physical fitness, and drive to perform at a high standard among military applicants in order to improve selection of new recruits and increase personnel management flexibility. ${ }^{9,10,17}$

Based on broad dimensions of normal personality, ${ }^{21}$ TAPAS measures narrow personality dimensions as well as dimensions of special interest to the military, which include a propensity to engage in physical conditioning. A version of the physical conditioning dimension has been used in other non-cognitive tests used by the U.S. military. It was first introduced as a militaryrelevant attribute in addition to traditional personality traits, early non-cognitive tests, Assessment of Background and Life Experiences, and a predictor of first-term enlisted attrition in U.S. Army trainees. ${ }^{22}$ Of note, the Assessment of Individual Motivation, a non-cognitive test 
given to non-high school graduate U.S. Army trainees, also included a physical conditioning dimension. ${ }^{23}$ More importantly, the physical conditioning dimension in each of these tests (Assessment of Individual Motivation and Assessment of Background and Life Experiences) measured desire to participate in sports and exercise.

Personality measures often have limited use in high-stakes testing situations, such as personnel selection, owing to the desire of respondents to answer questions favorably and to increase their likelihood of acceptance. ${ }^{9,10,17}$ Individuals taking TAPAS are asked to choose between two statements that are matched on social desirability and endorse the statement that is most like him/her. Each statement measures a different personality dimension important to job performance, thus making it difficult to simply choose the "correct" statement and the probability of "falsely representative" answers. The psychometric properties of TAPAS thereby limit an applicant's ability to "fake a score" or distort their responses, thus making it better suited for use as a military enlistment screening tool. ${ }^{24}$

The purpose of this study is to examine the TAPAS personality dimensions with a particular focus on the physical conditioning dimension as a possible predictor for subsequent overuse MSIs in the first 6 months of military service. Existing literature demonstrates that low levels of both fitness and physical activity are risk factors for MSIs and stress fractures. The a priori hypothesis was that men and women with lower TAPAS physical conditioning dimension scores would be at increased risk of both types of injury. There were no a priori hypotheses regarding any of the other dimensions. 


\section{Methods}

\section{Study Design and Population}

A retrospective cohort study of U.S. Army trainees was conducted to determine whether TAPAS personality dimension scores were associated with MSIs and stress fractures. Army applicants were administered TAPAS at Military Entrance Processing Stations where the test was operationalized. The fifteen TAPAS dimension scores for U.S. Army Active Duty trainees without prior military service who accessed in Fiscal Year $2010(\mathrm{~N}=15,082)$ were provided by the U.S. Army Research Institute for Social and Behavioral Sciences. These individuals were matched to accession and discharge data from the Defense Manpower Data Center and outpatient medical data from the Standard Ambulatory Data Record of the Military Health System Data Repository.

The study was approved by the Walter Reed Army Institute of Research IRB as a minimal risk protocol utilizing existing administrative and healthcare data, with a waiver of informed consent.

\section{Measures}

The Drasgow Consulting Group (rasgowassessments.com/) developed TAPAS under the Army’s Small Business Innovation Research grant program. It has been administered as a computerized adaptive test to some Army applicants at Military Entrance Processing Stations since July 2009 and all applicants in 2010. TAPAS utilizes a self-report, multidimensional pairwise preference algorithm that has been validated and deemed reliable. ${ }^{10}$ Each pairwise statement addresses one of the 15 different personality dimensions (Appendix A). ${ }^{17}$ Specifically, TAPAS measures: achievement, attention seeking, cooperation, dominance, even temperedness, generosity, intellectual efficiency, non-delinquency, optimism, order, physical conditioning, 
sociability, tolerance. ${ }^{9,10,24}$ These statements are matched in terms of social desirability. TAPAS scores are reported as Z-scores, ranging from -2.33 to 2.33 , and scores for each dimension were used as continuous variables. Applicants have 30 minutes to complete the assessment and scores for each dimension are then generated. During the study period, TAPAS scores were not used for selection purposes, but TAPAS was operationalized for certain categories of applicants at a later time. ${ }^{25}$ Specific TAPAS statements are proprietary information and are not available to the authors of this report, but some examples are available in other reports. ${ }^{16,17,26}$

Of all TAPAS dimensions evaluated for associations with MSIs and stress fractures, the primary dimension of interest was physical conditioning. The physical conditioning dimension was designed as an activity measure in that high-scoring individuals "tend to engage in activities to maintain their physical fitness and are more likely to participate in vigorous sports or exercise."17 One example of a paired statement for the physical conditioning dimension is:

- I like to exercise.

- I don't consider myself to be an athletic person.

The TAPAS physical conditioning dimension has also been shown to be predictive of soldiers' fitness level ratings (Army Physical Fitness Test score). ${ }^{17}$ Therefore, even though access to individual statements is unavailable, physical conditioning is considered to be a surrogate for a self-reported activity scale.

Outpatient diagnoses for overuse injuries, common in the military training environment, were separated into two mutually exclusive outcomes: stress fractures and all other MSIs. Overuse 
injuries in this study were characterized as one of the following: bone stress injuries, pains, sprains/strains, fasciitis/enthesopathy/bursitis, and tendonitis and arthropathies, based on ICD-9

diagnostic codes. These specific ICD-9 codes used have also been reported elsewhere, ${ }^{27,28}$ increasing validity.

Individuals were first identified for stress fractures per case definition previously described by Cowan et al. ${ }^{5}$ Inclusion criteria for stress fracture required two outpatient encounters for the same stress fracture diagnosis: ICD-9 codes 733.93 (tibia or fibula), 733.94 (metatarsals), and 733.95 (other bone). The first diagnosis must occur within 180 days of service and the second diagnosis $\geq 14$ days after the first. Individuals with an overuse MSI who did not meet the case definition for a stress fracture were defined as having an MSI. The MSI group included individuals with a diagnosis of equivocal stress fractures. The case definition for MSI was determined by Cowan and colleagues. ${ }^{27}$ Individuals with MSI and stress fractures were compared with individuals without overuse injuries.

\section{Statistical Analysis}

Data were analyzed in 2013-2015. Statistical analyses were performed using SAS, version 9.3. All analyses were stratified by sex and by type of injury (MSI or stress fracture). All TAPAS dimensions were evaluated for associations with MSIs or stress fractures considering each dimension's score as a continuous variable. Correlations between dimensions were also evaluated. Other covariates of interest included the following factors at accession: age (continuous), race (white, black, other), BMI (underweight, normal, overweight, obese), medical waivers (yes/no), education (other certificate, high school diploma, some college, Bachelor's 
degree or higher), and the military occupational specialty physical demand rating (light, medium, moderately heavy, heavy, very heavy).

Accession medical waivers are required for any military applicants who have a disqualifying medical condition. The physical demand rating for military occupational specialty, described in the Department of the Army Pamphlet $611-21,{ }^{29}$ rates the physical work requirement necessary under combat conditions; however, the intensity of initial entry training can vary depending on the military occupational specialty and physical demand rating. The covariates were used as control variables only. Crude incidence rates and rate ratios for location and type of injury (count data) were calculated using Poisson regression. AORs for all TAPAS dimensions and other covariates were calculated using logistic regression modeling. Parsimonious models were developed based on a significance level of 0.05 using forward selection methods. Model selection, including determination of which TAPAS dimensions to retain, was based on an evaluation of improvement in goodness-of-fit statistics, including the Akaike Information Criterion, significant associations between each dimension, and the endpoints and consistency between sexes and across types of injury. The final models considered included physical conditioning forced into the model, along with accession factors that had been found to be related to MSI or stress fracture.

\section{Results}

There were 13,145 men and 1,937 women who took TAPAS and accessed in Fiscal Year 2010. Table 1 provides the demographic characteristics of this study population. Owing to the large number of observations $(\mathrm{N}=15,082)$, very low correlations between most dimensions were 
statistically significant. However, most of the correlations were low (among men, the highest was 0.33 between dominance and achievement; among women, the highest was 0.37 between excitement and sociability).

Among male subjects, cumulative incidence of injuries in the first 180 days of service was $29 \%$ (3,610 had an MSI and 165 had a stress fracture). Among women, cumulative incidence of injuries was 55\% (1,020 had an MSI and 52 had a stress fracture). Table 2 presents the bivariate relationship (OR) between each TAPAS dimension score and MSI and stress fracture among men and women. Among all analyzed dimensions, physical conditioning was the only dimension that was significantly associated with both MSI and stress fracture for both men and women. The odds of MSIs significantly decreased with increasing physical conditioning scores for men $(\mathrm{OR}=0.83,95 \% \mathrm{CI}=0.79,0.86)$ and women $(\mathrm{OR}=0.77,95 \% \mathrm{CI}=0.70,0.85)$. For stress fractures, there was also an inverse association with physical conditioning and odds of injury for men $(\mathrm{OR}=0.66,95 \% \mathrm{CI}=0.56,0.78)$ and women $(\mathrm{OR}=0.59,95 \% \mathrm{CI}=0.42,0.82)$.

When the other TAPAS dimensions were considered individually, no consistent associations were found. Although the known risk factors for MSI and stress fracture are similar, ${ }^{5}$ no consistent patterns were found within each sex, or between men and women. Most (86\%) of the associations between the other dimensions and the outcomes were not statistically significant. Among men, generosity, intellectual efficiency, tolerance, and well-being were significantly but weakly associated with MSI. Self-control and order were significantly but weakly associated with stress fracture. Among women, none of the other dimensions were significantly associated with MSI or stress fracture on bivariate analysis. 
Table 3 presents the results from forward selection multivariate logistic regression models with physical conditioning forced in and other TAPAS dimensions free to enter based on their statistical significance and improvement of fit of the model. In addition to physical conditioning, the dimensions that were weak but statistically significant predictors for MSI among men included intellectual efficiency, sociability, tolerance, and well-being. Only physical conditioning was associated with stress fracture. The inclusion of these other variables into the model did not materially change the association between physical conditioning and risk of MSI or stress fracture. Further, only physical conditioning was a significant predictor of both MSI and stress fracture among women.

\section{Discussion}

The physical conditioning TAPAS dimension was a significant and consistent predictor of MSI and stress fracture among both men and women, strengthening the hypothesis that this dimension is a surrogate for a self-reported activity scale.

Army applicants are administered TAPAS at Military Entrance Processing Stations, using a computer-based platform. Typically, the entire instrument can be completed within 20 minutes, although a maximum of 30 minutes is allowed. TAPAS has been operationalized as a screening tool for Army applicants since July $2011,{ }^{25,30}$ but the individual dimensions have not been considered. No a priori hypotheses were postulated for the other 14 TAPAS dimensions; however, on the bivariate analysis among men, some were weakly but significantly associated with MSI but not stress fracture, or associated with stress fracture but not MSI. None of the 
dimensions were strongly associated with risk of injury, nor were they highly correlated with each other. None were associated with either endpoint among women, although this may be partially due to a lack of statistical power from a small female sample. The lack of consistency of effect across endpoints and sexes raises questions about the biological plausibility of the observed associations. Although the associations with the other dimensions are not so easily explained, the weak and inconsistent observed associations indicate that none of these dimensions is particularly important or operationally useful in identifying soldiers with potentially modifiable risk factors for injury. However, the physical conditioning dimension was a much stronger predictor of both endpoints among men. For these reasons, it is most likely that the observed associations for other dimensions among only men and only for MSIs are artificial.

Lower scores on the physical conditioning dimension have been found to be predictive of psychiatric disorders in two previous studies. ${ }^{31,32}$ In both of these studies, those with higher physical conditioning scores were less likely to receive an early discharge from the U.S. Army. In a separate study, measured fitness was found to be predictive of psychiatric disorders ${ }^{33}$ and both MSIs and stress fractures, ${ }^{4,5}$ as well as attrition. ${ }^{34}$ This conclusion strengthens the assumption that the physical conditioning dimension is a surrogate measure of physical activity, which is positively correlated with physical fitness. ${ }^{17}$

\section{Limitations}

Because specific TAPAS statements are proprietary information, they are not available to the authors of this report. However, this is not considered to be a major shortcoming of this research, as the psychometric theory that was involved in developing the entire instrument is of less 
interest than the potential application and usefulness as a military applicant screening tool. The physical conditioning dimension has shown that it can be useful for this purpose.

The relationship between TAPAS physical conditioning and actual measured fitness could be better quantified by combining existing TAPAS data with existing data from fitness tests conducted on all trainees. Fitness data were unavailable for this study. However, if the physical conditioning dimension is highly correlated with measured fitness, it would be possible to use the dimension as a valid screening instrument to identify those at higher risk of injury.

\section{Conclusions}

Because TAPAS is fully functional, and it provides a surrogate measure (physical conditioning) of physical activity, it has the potential to serve as a guide in U.S. Army accession policies, as well as other services, if replicated. The potential exists for applying the physical conditioning dimension to meet U.S. Army recruitment needs by using the dimension to "screen in" applicants who may be marginal (but trainable) candidates but whose physical conditioning score indicates they are less likely to develop an MSI, stress fracture, psychiatric disorder, or to be discharged before completion of service. The physical conditioning dimension might also be used as a differentiating factor among those candidates who were otherwise qualified, but may be at high risk for stress fracture or MSI ("screen out"). Future efforts should include application of the physical conditioning dimension of TAPAS testing in other services. The results of this study may be generalizable to other occupations, including firefighters, emergency personnel, and professional athletes, whose job functions require a high level of physical fitness. 


\section{Acknowledgments}

The authors thank LTC Paul O. Kwon, DO, MPH, and COL Earl H. Lynch, MD, MPH, for their careful review of the manuscript and Ms. Janice Gary, Preventive Medicine Branch, ManTech International Corporation, for her administrative support.

Material has been reviewed by the Walter Reed Army Institute of Research. There is no objection to its presentation or publication. The opinions or assertions contained herein are the private views of the author, and are not to be construed as official, or as reflecting true views of the Department of the Army or the Department of Defense.

This work was supported by the U.S. Army Research Institute for the Behavioral and Social Sciences.

No financial disclosures were reported by the authors of this paper. 


\section{References}

1. Hauret KG, Jones BH, Bullock SH, Canham-Chervak M, Canada S. Musculoskeletal injuries: description of an under-recognized injury problem among military personnel. Am J Prev Med. 2010;38(1S):S61-S70. http://dx.doi.org/10.1016/j.amepre.2009.10.021.

2. Armed Forces Health Surveillance Branch. Absolute and relative morbidity burdens attributable to various illnesses and injuries, U.S. Armed Forces, 2013. MSMR. $2014 ; 21(4): 2-7$

3. Armed Forces Health Surveillance Branch. Ambulatory visits among members of the Active Component, U.S. Armed Forces, 2013. MSMR. 2014;21(4):15-20.

4. Bedno SA, Cowan DN, Urban N, Niebuhr DW. Effect of pre-accession physical fitness on training injuries among U.S. Army recruits. Work (Reading, Mass.). 2013;44(4):509515.

5. Cowan DN, Bedno SA, Urban N, Lee DS, Niebuhr DW. Step test performance and risk of stress fractures among female Army trainees. Am J Prev Med. 2012;42(6):620-624. http://dx.doi.org/10.1016/j.amepre.2012.02.014.

6. Knapik JJ, Sharp MA, Canham-Chervak M, et al. Risk factors for training-related injuries among men and women in basic combat training. Med Sci Sports Exerc. 2001;33(6):946954. http://dx.doi.org/10.1097/00005768-200106000-00014.

7. Knapik JJ, Darakjy S, Hauret KG, et al. Increasing the physical fitness of low-fit recruits before basic combat training: an evaluation of fitness, injuries, and training outcomes. Mil Med. 2006;171(1):45-54. http://dx.doi.org/10.7205/MILMED.171.1.45. 
8. Jones BH, Knapik JJ. Physical training and exercise-related injuries. Surveillance, research and injury prevention in military populations. Sports Med. 1999;27(2):111-125. http://dx.doi.org/10.2165/00007256-199927020-00004.

9. $\quad$ Knapp DJ, Heffner TS. Expanded Enlistment Eligibility Metrics (EEEM): recommendations on a non-cognitive screen for new soldier selection. Arlington, VA: U.S. Army Research Institute for the Behavioral and Social Sciences; 2010. Technical Report No.: 1267.

10. Knapp DJ, Heffner TS. Tier One Performance Screen Initial Operational Test and Evaluation: Early Results. Arlington, VA: U.S. Army Research Institute for the Behavioral and Social Sciences; 2011. Technical Report.: 1283.

11. Penney LM, David E, Witt LA. A review of personality and performance: Identifying boundaries, contingencies, and future research directions. Hum Resour Manag Rev. 2011;21:297-310. http://dx.doi.org/10.1016/j.hrmr.2010.10.005.

12. Rothstein MG, Goffin RD. The use of personality measures in personnel selection: What does current research support? Hum Resour Manag Rev. 2006;16:155-180. http://dx.doi.org/10.1016/j.hrmr.2006.03.004.

13. Barrick MR, Mount MK. The big five personality dimensions and job performance: a meta-analysis. Pers Psychol. 1991;44(1):1-26. http://dx.doi.org/10.1111/j.17446570.1991.tb00688.x.

14. Stark S, Chernyshenko OS, Lee WC, et al. Optimizing prediction of attrition with the U.S. Army's Assessment of Individual Motivation (AIM). Mil Psychol. 2011;23:180-201. http://dx.doi.org/10.1080/08995605.2011.550234. 
15. White LA, Young MC, Heggestad ED, et al. Development of a non-high school diploma graduate pre-enlistment screening model to enhance the future force. Arlington, VA:

U.S. Army Research Institute for the Behavioral and Social Sciences; 2004.

16. Stark S, Chernyshenko OS, Drasgow F, et al. From ABLE to TAPAS: A new generation of personality tests to support military selection and classification decisions. Mil Psychol. 2014;26(3):153-164. http://dx.doi.org/10.1037/mil0000044.

17. Drasgow F, Stark S, Chernyshenko OS, Nye CD, Hulin CL. Development of the Tailored Adaptive Personality Assessment System (TAPAS) to Support Army Selection and Classification Decisions. Fort Belvoir, VA: U.S. Army Research Institute for the Behavioral and Social Sciences; 2012. Technical Report.: 1311.

18. Allen MT, Cheng YA, Putka DJ, Hunter A, White L. Analysis and findings. Arlington, VA: U.S. Army Research Institute for the Behavioral and Social Sciences; 2010.

19. Hough LM, Eaton NK, Dunnette MD, Kamp JD, McCloy RA. Criterion-related validities of personality constructs and the effect of response distortion on those validities. J Appl Psychol. 1990;75(5):581-595. http://dx.doi.org/10.1037/0021-9010.75.5.581.

20. Houston JS, Borman WC, Farmer WL, Bearden RM. Millington TN. Navy Personnel Research Studies, and Technology Division, Bureau of Navy Personnel (NPRST/PERS1); 2006.

21. Goldberg LR. An alternative "description of personality": the big-five factor structure. $J$ Pers Soc Psychol. 1990;59(6):1216-1229. http://dx.doi.org/10.1037/00223514.59.6.1216.

22. White LA, Young MC, Rumsey MG. ABLE implementation issues and related research. Mahwah, NJ: Erlbaum; 2001. 
23. Young MC, McCloy RA, Waters BK, White LA. An overview of AIM and the preliminary efforts to support its operational use. Alexandria, VA: U.S. Army Research Institute for the Behavioral and Social Sciences; 2004.

24. Stark S, Chernyshenko OS, Drasgow F. An IRT approach to constructing and scoring pairwise preference items involving the stimuli on different dimensions: the multiunidimensional pairwise-preference model. Appl Psychol Meas. 2005;29:184-203. http://dx.doi.org/10.1177/0146621604273988.

25. Department of the Army. Implementation of the Tier 1 Performance Screen (TOPS) Change 1. In: Personnel OotDCoSf, ed.; Washington, DC: U.S. Army; 2011.

26. Heffner TS, Campbell RC, Drasgow F. Select for Success: A Toolset for Enhancing Soldier Accessioning. U.S. Army Research Institute for the Social and Behavioral Sciences; 2011.

27. Cowan DN, Bedno SA, Urban N, Yi B, Niebuhr DW. Musculoskeletal injuries among overweight army trainees: incidence and health care utilization. Occup Med. 2011;61:247-252. http://dx.doi.org/10.1093/occmed/kqr028.

28. Department of Defense. AMSARA: Attrition \& Morbidity Data for 2012 Accessions Annual Report 2013. Washington, DC: Department of Defense; 2013.

29. Department of the Army. Personnel selection and classification: Military Occupational Classification and Structure. In: Headquarters DotA, ed. Vol 611-21; Washington, DC: U.S. Army; 2007.

30. Department of the Army. Implementation of the Tier 1 Performance Screen (TOPS). In: Personnel OotDCoSf, ed.; Washington, DC: U.S. Army; 2009. 
31. Niebuhr DW, Gubata ME, Oetting AA, et al. Personality Assessment Questionnaire as a pre-accession screen for risk of mental disorders and early attrition in U.S. Army recruits. Psychol Serv. 2013;10(4):378-385. http://dx.doi.org/10.1037/a0032783.

32. Gubata ME, Oetting AA, Weber N, et al. A noncognitive temperament test to predict risk of mental disorders and attrition in U.S. Army recruits. Mil Med. 2012;177:374-379. http://dx.doi.org/10.7205/MILMED-D-11-00297.

33. Gubata ME, Urban N, Cowan DN, Niebuhr DW. A prospective study of physical fitness, obesity, and the subsequent risk of mental disorders among health young adults in Army training. J Psychosom Res. 2013;75(1):43-48. http://dx.doi.org/10.1016/j.jpsychores.2013.04.003.

34. Niebuhr DW, Scott CT, Powers TE, et al. Assessment of recruit motivation and strength study: Preaccession physical fitness assessment predicts early attrition. Mil Med. 2008;173:555-562. http://dx.doi.org/10.7205/MILMED.173.6.555. 
Table 1. Demographic Characteristics of TAPAS Study Population by Sex

\begin{tabular}{|c|c|c|c|c|}
\hline Variable & \multicolumn{2}{|c|}{$\begin{array}{c}\text { Men } \\
\mathrm{N}=\mathbf{1 3 , 1 4 5}\end{array}$} & \multicolumn{2}{|c|}{$\begin{array}{c}\text { Women } \\
\mathrm{N}=1,937 \\
\end{array}$} \\
\hline \multicolumn{5}{|l|}{ Age (years) } \\
\hline \multirow[t]{2}{*}{ Mean (SD) } & \multicolumn{2}{|c|}{$21.6(4.2)$} & \multicolumn{2}{|c|}{$21.9(4.6)$} \\
\hline & $\mathbf{N}$ & $\%$ & $\mathbf{N}$ & $\%$ \\
\hline \multicolumn{5}{|l|}{ Race } \\
\hline White & 10,443 & 79.4 & 1,318 & 68.0 \\
\hline Black & 1,378 & 10.5 & 419 & 21.6 \\
\hline Other & 1,324 & 10.1 & 200 & 10.3 \\
\hline \multicolumn{5}{|l|}{ BMI } \\
\hline Underweight & 153 & 1.2 & 35 & 1.8 \\
\hline Normal & 5,739 & 43.7 & 1,143 & 59.0 \\
\hline Overweight & 5,184 & 39.4 & 734 & 37.9 \\
\hline Obese & 2,069 & 15.7 & 25 & 1.3 \\
\hline \multicolumn{5}{|l|}{ PDR } \\
\hline Light/Medium & 487 & 3.7 & 231 & 11.9 \\
\hline Moderately heavy & 1,558 & 11.9 & 341 & 17.6 \\
\hline Heavy & 1,480 & 11.3 & 438 & 22.6 \\
\hline Very heavy & 8,943 & 68.0 & 807 & 41.7 \\
\hline \multicolumn{5}{|l|}{ Medical waiver } \\
\hline No medical waiver & 12,377 & 94.2 & 1,833 & 94.6 \\
\hline Medically waived & 768 & 5.8 & 104 & 5.4 \\
\hline \multicolumn{5}{|l|}{ Education } \\
\hline Other degree & 668 & 5.1 & 66 & 3.4 \\
\hline HS diploma & 10,024 & 76.3 & 1,425 & 73.6 \\
\hline Some college & 1,492 & 11.4 & 263 & 13.6 \\
\hline$\geq$ Bachelor's & 961 & 7.3 & 183 & 9.4 \\
\hline \multicolumn{5}{|l|}{ AFQT score } \\
\hline 93-99 (high score) & 1,157 & 8.8 & 100 & 5.2 \\
\hline $65-92$ & 4,753 & 36.2 & 562 & 29.0 \\
\hline $50-64$ & 2,999 & 22.8 & 475 & 24.5 \\
\hline $30-49$ & 4,048 & 30.8 & 776 & 40.1 \\
\hline 11-29 (low score) & 188 & 1.4 & 24 & 1.2 \\
\hline
\end{tabular}


Table 2. Bivariate ORs For Overuse Musculoskeletal Injuries and Stress Fractures With TAPAS Dimensions, Stratified by Sex

\begin{tabular}{|c|c|c|c|c|}
\hline \multirow[b]{2}{*}{$\begin{array}{l}\text { TAPAS } \\
\text { Dimension }\end{array}$} & \multicolumn{2}{|c|}{ Men } & \multicolumn{2}{|c|}{ Women } \\
\hline & $\begin{array}{c}\text { MSI } \\
\text { OR }(95 \% \mathrm{CI}) \\
\end{array}$ & $\begin{array}{c}\text { Stress Fracture } \\
\text { OR }(95 \% \mathrm{CI})\end{array}$ & $\begin{array}{c}\text { MSI } \\
\text { OR }(95 \% \mathrm{CI}) \\
\end{array}$ & $\begin{array}{c}\text { Stress Fracture } \\
\text { OR }(95 \% \text { CI })\end{array}$ \\
\hline Achievement & $1.04(1.00,1.08)$ & $1.02(0.87,1.19)$ & $1.00(0.91,1.10)$ & $1.24(0.93,1.66)$ \\
\hline Adjustment & $1.04(1.00,1.08)$ & $1.04(0.89,1.22)$ & $0.97(0.89,1.07)$ & $0.90(0.67,1.21)$ \\
\hline Cooperation & $1.02(0.98,1.06)$ & $0.98(0.84,1.15)$ & $1.00(0.91,1.10)$ & $1.05(0.79,1.41)$ \\
\hline Dominance & $1.02(0.98,1.05)$ & $0.95(0.82,1.11)$ & $1.02(0.93,1.12)$ & $0.93(0.70,1.23)$ \\
\hline Even tempered & $1.01(0.97,1.05)$ & $1.13(0.96,1.32)$ & $0.97(0.88,1.06)$ & $1.01(0.76,1.36)$ \\
\hline Excitement & $0.97(0.94,1.01)$ & $0.90(0.77,1.05)$ & $1.04(0.94,1.14)$ & $0.90(0.67,1.22)$ \\
\hline $\begin{array}{l}\text { Generosity } \\
\text { Intellectual }\end{array}$ & $1.06(1.02,1.11)^{* * *}$ & $1.11(0.95,1.30)$ & $0.93(0.84,1.02)$ & $0.77(0.58,1.04)$ \\
\hline $\begin{array}{l}\text { efficiency } \\
\text { Non- }\end{array}$ & $1.07(1.03,1.12)^{* * * *}$ & $1.15(0.98,1.34)$ & $1.06(0.96,1.17)$ & $1.12(0.83,1.51)$ \\
\hline delinquency & $1.01(0.97,1.05)$ & $1.04(0.89,1.22)$ & $0.97(0.88,1.07)$ & $0.82(0.61,1.11)$ \\
\hline Order & $1.03(0.99,1.07)$ & $1.19(1.02,1.40)^{*}$ & $1.02(0.94,1.12)$ & $1.02(0.78,1.35)$ \\
\hline $\begin{array}{l}\text { Physical } \\
\text { conditioning }\end{array}$ & $0.83(0.79,0.86)^{* * * *}$ & $0.66(0.56,0.78)^{* * * *}$ & $0.77(0.70,0.85)^{* * * *}$ & $0.59(0.43,0.81)^{* * *}$ \\
\hline Self-control & $1.05(1.01,1.09)^{*}$ & $1.19(1.01,1.39)^{*}$ & $1.07(0.97,1.17)$ & $1.00(0.75,1.35)$ \\
\hline Sociability & $1.03(0.99,1.07)$ & $0.88(0.75,1.03)$ & $0.98(0.89,1.08)$ & $0.95(0.71,1.28)$ \\
\hline Tolerance & $1.08(1.04,1.13)^{* * * *}$ & $1.01(0.86,1.19)$ & $0.92(0.84,1.01)$ & $0.99(0.73,1.33)$ \\
\hline Well being & $0.95(0.92,0.99)^{*}$ & $0.97(0.83,1.14)$ & $1.04(0.95,1.14)$ & $1.08(0.81,1.43)$ \\
\hline
\end{tabular}

Note: Boldface indicates statistical significance $(* p<0.05 ; * * p<0.01 ; * * * p<0.001)$.

TAPAS, Tailored Adaptive Personality Assessment System; MSI, musculoskeletal injury 
Table 3. Sex-Stratified, AORs For Overuse Musculoskeletal Injuries and Stress Fractures With TAPAS Dimensions

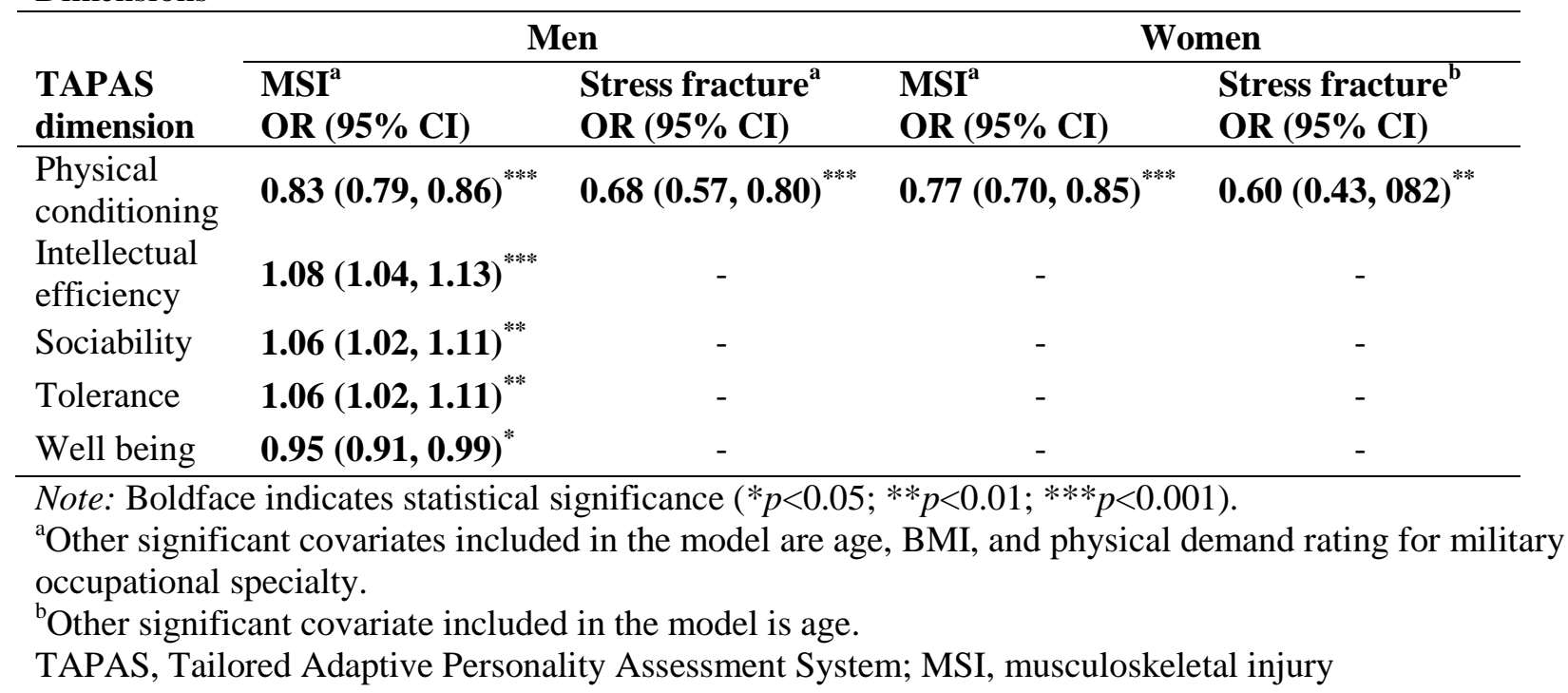

